\title{
Advances in aluminium alloy products for structural applications in transportation
}

\author{
J.T. STALEY and D.J. LEGE
}

Aluminum Company of America, 100 Technical Drive, Alcoa Technical Center, Alcoa Center, PA 15069, U.S.A.

\begin{abstract}
This paper describes the needs of the aviation and automotive markets for structural materials and presents examples of developments of aluminum alloy products to fill these needs. Designers of aircraft desire materials which will allow them to design lightweight, cost-effective structures which have the performance characteristics of durability and damage tolerance. Their needs are being met by new and emerging materials varying from $\mathrm{Al}$-Li alloys for thick structure, high-strength plate and extrusions for wings, and new monolithic and aluminum-fiber laminates for fuselages. Increase in fuel economy because of lighter weight structure is the driving force for aluminum alloys in the automotive market, and cost is extremely important. Mechanical properties for automotive use also depend on the application, and corrosion resistance must be adequate. For "hang-on" components such as fenders and hoods, formability is typically the limiting mechanical property. Strength must be adequate to resist denting at a thickness which offers cost-effective weight savings over steel. Because formability often decreases with increasing yield strength, alloys which are highly formable in the T4 temper and which age harden during the paint bake operation were developed. Alloys such as 6009 and 6010 are now being challenged by 2008,6111 and 6016 . Body structure components must be made from materials which absorb energy and fail gracefully during a crash. Such components for an automotive space frame are being die cast from an Al-Si-Mg alloy. These ductile die castings are joined to thin $6 \mathrm{XXX}$ extrusions which must combine formability, strength, ductility and the ability to deform plastically on impact. Bumpers must combine strength and adequate formability; in the event that current alloys are inadequate for future needs, a new 7XXX alloy offers an improved combination of properties.
\end{abstract}

\section{INTRODUCTION}

Typically, material selection for structural applications in aircraft depends mainly on the performance requirements, Figure 1, but manufacturing considerations have equal if not higher importance for automotive applications. This paper reviews the property requirements for different portions of the aircraft based mainly on performance requirements and points out where manufacturing considerations begin to outweigh performance considerations. Most of the section on aircraft is condensed from another publication [1]. The paper also reviews the property requirements for automotive hang-on components, body structure and bumpers. A description is provided of recently developed and embryonic concepts of aluminum based materials for both applications.

\section{AIRCRAFT APPLICATIONS}

\section{FUSELAGE}

The fuselage can be divided into three areas: crown, sides and bottom. Predominant loads during flight are tension in the crown, compression in the bottom and shear in the sides. For commercial jetliners and military transport planes, the fuselage is typically constructed of a skin over stringers (longitudinal) and 
Material properties:
Corrosion
CYS = Compressive Yield Strength
$\mathrm{E}=$ Modulus
FAT $=$ Fatigue
( ) = Important, but not critical, design requirement

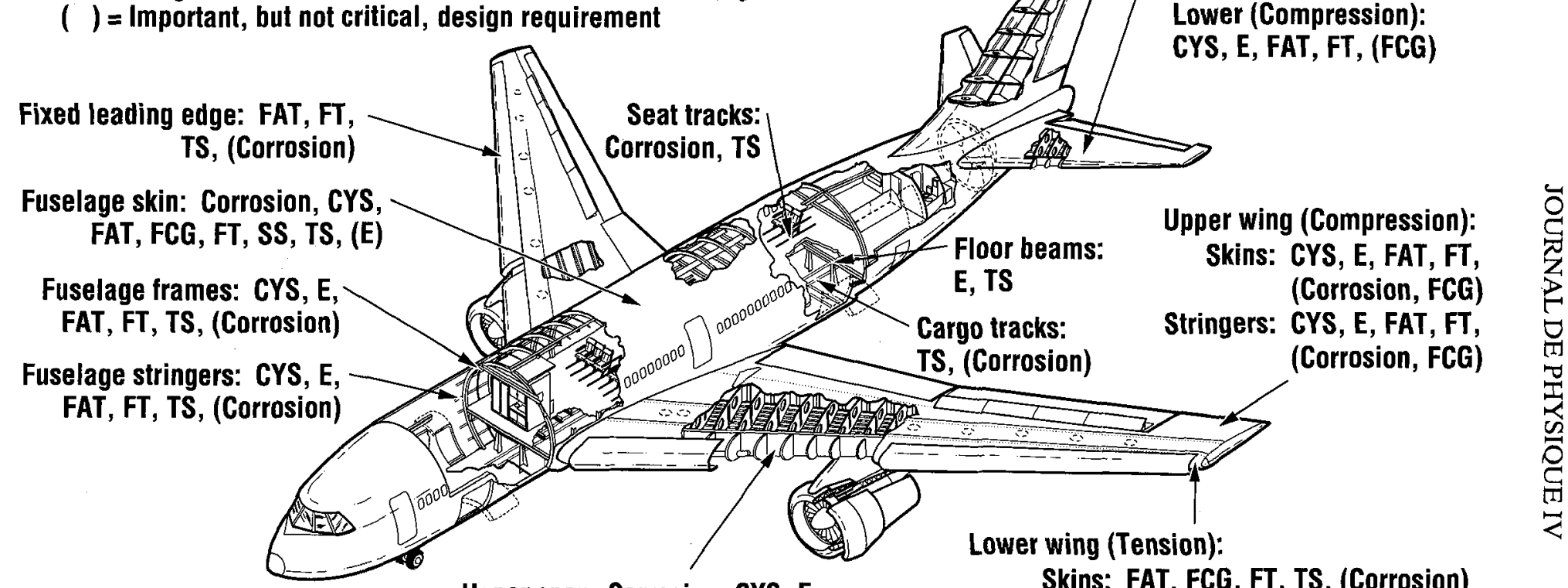

Upper spar: Corrosion, CYS, E,

Skins: FAT, FCG, FT, TS, (Corrosion) (FAT, FCG, FT) Stringers: FAT, FT, TS, (Corrosion, FCG)

Lower spar: FAT, FCG, FT, TS, (Corrosion)

\section{Property Requirements for Jetliner and Military Transport Applications}


frames (circumferential). In high performance military aircraft, thick bulkheads are used rather than frames. Strength, Young's modulus, fatigue initiation, fatigue crack growth, fracture toughness and corrosion are all important, but fracture toughness is often the limiting design consideration.

\section{Fuselage Skin}

C188: The most recent fuselage skin material is a proprietary Alcoa alclad product which has been specified for the Boeing 777 jetliner. This material was developed to meet the strength-fracture toughness targets established by Boeing for an improved fuselage skin material. Moreover, fatigue cracks grow half as fast in this material as in alclad 2024-T3 sheet at high levels of peak stress intensity factor $(>22 \mathrm{MPa} \sqrt{\mathrm{m}}$ ). The higher toughness and greater resistance to the growth of fatigue cracks save weight by eliminating tear straps. Stringent controls on both chemical composition and processing are required to meet the rigorous material requirements.

6013-T6: Alloy 6013-T6 sheet was the baseline material for the skin for the P7 ASW aircraft replacement for the P3. The P7 program was canceled, however, and no service experience with 6013-T6 was developed. Compared to alclad 2024-T3, 6013-T6 sheet is 3\% less dense and develops $30 \%$ higher yield strength in compression and $12 \%$ higher yield strength in tension with comparable toughness and resistance to the growth of fatigue cracks. Bare and alclad 6013-T6 have been considered for the fuselage of jetliners, and corrosion fatigue tests indicate that the clad product is superior. The relationship between the metallurgical characteristics of 6013-T6 and its microstructure has not been established to the extent that it has for the older materials. This material exhibits a moderate volume fraction of a needle-shaped precipitate which may be either $\mathrm{Mg}_{2} \mathrm{Si}$ or an $\mathrm{Al}-\mathrm{Mg}-\mathrm{Si}-\mathrm{Cu}, \mathrm{Q}$, phase. A low volume fraction of platelets of metastable $\mathrm{Al}_{2} \mathrm{Cu}, \Theta^{\prime}$, phase may also be present. Particles of $\mathrm{Q}$ and $\Theta$ phase have been detected in grain boundaries. These are probably responsible for the tendency for intergranular corrosion. This corrosion does not lead to exfoliation corrosion, however, because the grain structure is recrystallized and equiaxial. The material also contains a low volume fraction of $\mathrm{Al}_{12} \mathrm{Mn}_{3} \mathrm{Si}$ dispersoids which exert control over recrystallized grain size and coarse intermetallic particles containing Fe and Si which affect fracture toughness.

Al-Li: 8090 and 2091 have been considered for fuselage skins for jetliners in the U.S. and Europe. They offer 6-7\% weight savings over 2024-T3 because of lower density and exhibit higher modulus and superior resistance to the growth of fatigue cracks. Concerns over SCC, fracture toughness and stability of properties after long times at modest elevated temperatures have led to the development of special fabricating procedures and tempers. Many of the metallurgical characteristics of $\mathrm{Al}-\mathrm{Li}$ alloy products such as 8090 and 2091 sheet are attributed to a high volume fraction of ordered $\mathrm{Al}_{3} \mathrm{Li}, \delta$, precipitates. These ordered spherical particles are sheared by pairs of dislocations; the first dislocation disrupts the order which is restored by the following one. This behavior serves to localize deformation as bands on particular slip planes. The slip bands concentrate the stress on grain boundaries which may contain equilibrium precipitates and promote intergranular fracture. The superior crack growth performance of these materials under cyclic loading conditions is attributed to the concentration of slip forcing the advancing crack to follow a particular set of slip bands in a grain. When a grain boundary is reached, the crack must abruptly change direction as it grows. This induced tortuosity decreases the average rate of growth of the fatigue crack. The Al-Mg-Li- $\mathrm{Zr}$ alloy 01420 has been used in Russian aircraft for fuselage skin sheet material. Based on tests at several U.S. commercial and military airframe builders and at U.S. military laboratories, alloy 01420 was not recommended for use on civil or military aircraft because its inferior combination of strength, fracture toughness and fatigue characteristics outweighed the density advantage.

Fiber-Metal Laminates: The newer aluminum alloys offer cost-effective weight savings that are lower than those claimed by a more expensive graphite-epoxy composite $(\mathrm{Gr} / \mathrm{Ep})$ fuselage. A new family of glass fiber-aluminum alloy laminates known as GLARE, however, offers weight savings competitive with $\mathrm{Gr} / \mathrm{Ep}$ while retaining the advantages of aluminum at a lower total cost than $\mathrm{Gr} / \mathrm{Ep}$. Compared to 2024-T3, GLARE offers lower density, higher strength and damage tolerance and much greater resistance to the growth of fatigue cracks. Performance on the barrel test, which measures fatigue resistance of a section of a fuselage under simulated service stresses, is far superior to that of any aluminum alloy product. The non-metallic (prepreg) layers in GLARE are about $0.1 \mathrm{~mm}$ thick and consist of S2 glass fibers embedded in an epoxy resin. The aluminum sheet in current versions is either 
2024-T3 or 7475-T76 and is about $0.3 \mathrm{~mm}$ thick. The high strength of GLARE laminates is attributed to the strength of the glass fibers, while the high damage tolerance is attributed to the aluminum alloy sheet. The resistance to the initiation of fatigue cracks is controlled by the resistance of the aluminum sheet, while the resistance to the growth of the fatigue cracks is attributed to the bridging effect of the fibers and to some controlled debonding at the epoxy-aluminum sheet interface. While GLARE is more expensive than aluminum alloy sheet, economies of construction promise a cost-effective structure. Based on expressed interest by manufacturers of airframes, the next generation jetliners may well have at least a portion of the fuselage skin fabricated from GLARE.

\section{Fuselage Stringers and Frames}

7050-T76 Sheet and Extrusions: This material solves the corrosion problems with 7075-T6 with no strength penalty. Alloy 7050-T76 products match the strength of 7075-T6 with higher toughness, superior fatigue characteristics and much higher resistances to exfoliation corrosion and SCC. The observation that alloy 7050 develops a more attractive combination of strength, corrosion characteristics and SCC resistance is attributed primarily to the increased copper content. The higher copper content provides a modification in the relative differences in electrochemical potential between matrix and grain boundary regions by the diffusion of copper into $\eta$ phase and $\eta$ ' phase particles during the overaging step and to a reduction in resolved stress on the grain boundaries because the incoherent $\eta$ phase particles minimize strain concentration. This material is being evaluated to replace 7075-T6 sheet and extrusions for future designs and as retrofits for problem parts.

7150-T77 Extrusions: This material offers even higher strength with durability and damage tolerance characteristics matching or exceeding those of 7050-T76. Extrusions in 7150-T77 have been selected by Boeing as fuselage stringers for the upper and lower lobes of the new 777 jetliner because of the superior combination of strength, corrosion and SCC characteristics and fracture toughness. The fracture toughness is attributed to the controlled volume fraction of coarse intermetallic particles and unrecrystallized grain structure, while the combination of strength and corrosion characteristics is attributed to the size and spatial distribution and the copper content of $\eta$ and $\eta$ ' precipitates produced by a proprietary process. These particles induce dislocations to bypass them by looping and minimize electrochemical differences between matrix and grain boundaries.

7055-T7X: This material is under development by Alcoa but is not yet commercially available. The goal is to provide higher strength than 7150-T77 with higher formability and comparable fracture toughness and resistances to exfoliation corrosion and SCC. The approach is to develop a microstructure of $\eta$ and $\eta^{\prime}$ precipitates in a material having a fine grain size by careful control of thermomechanical practices.

\section{Euselage Bulkheads}

New alloys containing about $1.5 \% \mathrm{Li}$ are being developed for evaluation as thick structure for high performance military aircraft. The goals are: 1) strength and toughness at least equivalent to 2124-T8, 2) no loss in toughness with elevated temperature exposure, 3) resistant to exfoliation corrosion and to SCC in the short-transverse direction at $172 \mathrm{MPa}, 4$ ) minimal anisotropy, 5) 5\% lower density and $7 \%$ higher modulus than 2124 and 6) Significantly higher resistance to the growth of fatigue cracks compared to 2124-T8 [2].

\section{WING}

The wing box, the part of the wing that carries the loads, consists of top and bottom covers (skins and longitudinal members; i.e., stringers), spars that create the sides of the wing box and ribs (transverse) that keep the covers in shape. The greatest weight of the wing is in skins and stringers, so development efforts have concentrated on requirements for these components. Compressive yield strength and modulus of elasticity in compression are the static material properties that influence the design of the top skin-stringer, while tensile strength, tensile yield strength and tensile modulus are the static material properties that influence the design of the lower skin-stringer. In addition, the wing is subjected to alternating loads caused during flight and while taxiing. Thus, fatigue resistance and damage tolerance are also important. Corrosion resistance is also important, as is SCC resistance of thick sections. 
Spars, which run the length of the wing, are usually composed of a stiffened web plate and have an extruded or bent sheet metal spar cap. For those designs which use a built-up spar, the alloy used for the upper spar cap is usually the same one used for the upper wing skin, and the alloy used for the bottom spar cap is usually the same one used for the lower wing skin. Ribs are usually constructed using stiffened 7075-T6 sheet/extrusions or machined plate. No alloys have been designed expressly for spars or ribs.

Leading and trailing edges are used to improve the aerodynamics of the airplane and reduce the take-off and landing speed. These elements of the wing are not primary load carrying structures. Fatigue, bending and torsional stiffness and resistance to hail damage are some of the design considerations.

\section{Upper Wing Materials}

7150-T77: The T77 temper for 7150 was developed in response to a need for improved corrosion resistance relative to 7150 in T6 or T61 tempers. Alloy 7150-T77 plate and extrusions develop the same mechanical properties as do their counterparts in T6 or T61 tempers with significantly improved resistances to both exfoliation corrosion and SCC. The first application was on the C17. This saved a considerable amount of weight because corrosion performance of 7150-T6 and T61 was deemed to be inadequate by the Air Force for this application. The combination of strength and corrosion characteristics of 7150-T77 is attributed to proprietary processing. This processing promotes the development of a precipitate structure which effectively resists the passage of dislocations equivalent to that provided by the T6 temper and simultaneously minimizes the electrochemical differences between the matrix and grain boundaries.

7055-T77: The implementation of the T77 temper for 7150 was followed by development of a proprietary material having higher strength for compressively loaded structure. Alloy 7055-T77 plate and extrusions offer a strength increase of about $10 \%$ relative to that of 7150 -T6 (almost $30 \%$ higher than that of 7075-T76). They also provide the high resistance to exfoliation corrosion of 7075-T76 with fracture toughness and resistance to the growth of fatigue cracks similar to that of 7150-T6. In contrast to the usual loss in toughness of $7 \mathrm{XXX}$ products at cryogenic temperatures, plane strain fracture toughness of $7055-\mathrm{T} 77$ at $-65^{\circ} \mathrm{F}\left(219^{\circ} \mathrm{K}\right)$ is similar to that at room temperature. Resistance to SCC is intermediate to those of 7075-T6 and 7150-T77. The attractive combination of properties of 7055-T77 is attributed to its high ratios of $\mathrm{Zn} / \mathrm{Mg}$ and $\mathrm{Cu} / \mathrm{Mg}$. When processed to the $\mathrm{T} 77$ temper, this composition provides a microstructure at and near grain boundaries that is resistant to intergranular fracture and to intergranular corrosion with a matrix microstructure that resists strain localization.

X2095-T8 Plate: This Al-Li alloy was developed by Martin-Marietta for weldable space structures. It develops high strength with a density lower than that of the $7 \mathrm{XXX}$ alloys. The $1.5 \%$ lithium content is closer to that of alloy 2020 developed in the 1950 s than it is to that of the Al-Li alloys developed in the 1980s. The high strength is attributed to a high volume fraction of several types of precipitates which form on different habit planes in the matrix. Fracture toughness of alloy X2095 products at comparable strength levels is higher than that of $\mathrm{Al}-\mathrm{Li}$ alloys containing higher lithium, but available information indicates that the combination of specific strength and fracture toughness is inferior to that of 7055-T77.

Alloy X7093/SiC/15p-T6 Extrusions: Because of its high compressive yield strength and elastic modulus, this discontinuously reinforced aluminum metal matrix composite (DRA) would provide significant weight savings on the portions of the wing exposed to high compressive loads. DRA materials are beginning to be specified for niche applications on both military and commercial aircraft, but fracture toughness would have to be improved, however, before this material would be favorably considered for wing structure. The excellent elastic modulus of this wrought powder metallurgy product is due to the 15 volume percent of $\mathrm{SiC}$ particulate which also contributes to the low fracture toughness.

Continuously Reinforced Aluminum: An experimental aluminum wing cover reinforced with continuous ceramic fibers was evaluated for military aircraft. The method of construction employed, however, is not cost effective, particularly for commercial aircraft. 
Al-Graphite Fiber: A structural laminate composed of thin sheets of aluminum alloy bonded to graphite fibers would also provide the specific stiffness required, but potential problems with galvanic corrosion between the fibers and the matrix must be solved.

Aluminum-beryllium Alloys: These materials offer high specific modulus and can be fabricated using economical ingot metallurgy processes. Concerns regarding toxicity of fumes or dust must be addressed before the technical capabilities can be realized.

Amorphous Aluminum Alloys: Bench-scale products of aluminum alloys exhibiting structures which are either completely or mostly amorphous have exhibited tensile strengths up to twice that of 7075-T6. Tensile ductility of the initial materials were low, but later results indicate that useful ductility can be achieved. Much more work is needed to determine whether these materials can be used for airframe applications.

\section{Lower Wing Materials}

The 600-800 passenger jetliner that is contemplated provides manufacturing challenges. Because of the large size of the wing, age-forming is a preferred method of forming wing skins. The current materials used for the lower wing skins of jetliners, 2024-T3 and 2324-T39, are naturally aged, so questions have been raised regarding their suitability for age-forming. Any new candidates for lower wing skin material for this new plane must be age formable.

7475-T73: Plate in this alloy is being considered for the lower wing skin of jetliners which will use age-forming to manufacture the wing. While 7475 sheet and plate has found use in high performance military aircraft because of its superior combination of strength and fracture toughness, 7475-T73 plate would be a new material for lower wing skins of jetliners. Questions regarding fracture toughness at the low temperatures encountered at high altitudes are being resolved.

8090-T86: Both plate and extrusions are also being considered as a material for the lower wing skin of jetliners. They promise weight savings because of lower density, and the materials are age-formable. Concerns regarding deviation of fatigue cracks from a path 90 degrees to the applied load, thermal stability and fracture toughness are being addressed to determine their relevance and impact.

Other Al-Li Alloy Plate: Russian investigators are experimenting with Al-Li alloys containing scandium, but properties of products in such alloys are sketchy and unconfirmed. Scandium forms $\mathrm{Al}_{3} \mathrm{Sc}$ in aluminum alloys, a dispersoid which has the same $\mathrm{L} 1_{2}$ crystal structure as the metastable $\mathrm{Al}_{3} \mathrm{Zr}$ found in modern $7 \mathrm{XXX}$ and $\mathrm{Al}-\mathrm{Li}$ alloys. Aluminum producers are doing research on next generation $\mathrm{Al}-\mathrm{Li}$ alloys, but sufficient information is not available to allow a comparison between these developmental materials and commercially established ones.

Fiber-Metal Laminates: The high durability and damage tolerance of this class of hybrid materials makes them strong candidates for structural parts such as the lower wing. Fokker has been performing "in-service" evaluations of portions of a lower wing on one of their commercial aircraft. The ARALL versions (aramid fibers) offer lower density than GLARE (glass fibers), but some manufacturers have expressed concern over possible problems with degradation of the aramid fibers even though they are only exposed at the edges of the laminate.

\section{Fixed Leading Edge}

Alloy 2090-T84 sheet has been specified on several new commercial aircraft. It saves weight because of its low density combined with ultimate longitudinal tensile strength equaling that of 7075-T76, superior resistance to the growth of fatigue cracks and acceptable fracture toughness.

\section{EMPENNAGE}

The empennage is the tail of the airplane and consists of a horizontal stabilizer, a vertical stabilizer, elevators and rudders. The horizontal stabilizer is like an upside down wing whose span is roughly $50 \%$ that of the wing. Structural design of both the horizontal and vertical stabilizers is essentially the same 
as for the wing. Both upper and lower surfaces of the horizontal stabilizer are often critical in compression due to up and down bending. Consequently, modulus of elasticity in compression is the most important property.

The higher strength and fracture toughness of the modern Li-free monolithic materials do not save enough weight to make them cost effective. However, the combination of low density and high stiffness of Al-Li alloys such as 8090 and 2090 and of ARALL fiber composites make them strong candidates for horizontal stabilizers of future jetliner and military transport aircraft.

\section{SUPPORTING STRUCTURE}

Supporting structures such as attachments of the wings to the fuselage and attachments of the landing gear to the wings are designed for strength, fatigue and fracture toughness. Resistance to SCC is extremely important for thick parts. Alloy 7055-177 forgings are now available for test and evaluation. Preliminary test data show a significant improvement in the combination of strength and fracture toughness compared with 7050-T74 at comparable resistance to SCC.

\section{AUTOMOTIVE}

Automotive applications which utilize aluminum alloys include hang-on components, bumpers and space frames. Unique properties are required for each specific application and manufacturer, so a wide range of alloys and product forms are used to meet these needs. The driving force for the use of aluminum in automotive components is weight savings for improved fuel economy. Unlike the airframe industry, however, cost premiums for weight savings are almost negligible.

\section{HANG-ON COMPONENTS}

Hoods, deck lids and doors are examples of automotive hang-on components made from sheet alloys [3]. Mechanical property, formability and surface finish requirements for the portions of these components which are visible (outer panels) differ from those for hidden parts (inner panels), but corrosion resistance requirements are similar. In general, conventional nonheat-treatable $5 \mathrm{XXX}$ alloys without copper are expected to exhibit the best resistance to general corrosion and pitting, but perhaps the least resistance to galvanic corrosion (relative to galvanic couples with steel). Although hang-on panels are typically protected by organic coating systems, these coatings are not always effectively utilized in certain automotive assembly crevice regions employing both steel and aluminum (i.e., hinges). Thus, potential for galvanic corrosion must be considered. Typical mechanical properties of aluminum auto body sheet alloys used worldwide are shown in Table 1.

Table 1

Typical Mechanical Properties of Aluminum Auto Body Sheet Alloys

Uniaxial Tension Properties (Transverse Test Orientation)

\begin{tabular}{|c|c|c|c|c|c|c|}
\hline \multirow[b]{2}{*}{$\begin{array}{l}\text { Alloy- } \\
\text { Temper }\end{array}$} & \multicolumn{5}{|c|}{ As-Received } & \multirow{2}{*}{$\begin{array}{c}\text { After Bake } \\
\text { Paint } \\
\text { Yield } \\
\text { Strength, } \\
\mathrm{MPa}\end{array}$} \\
\hline & $\begin{array}{c}\text { Yield } \\
\text { Strength, } \\
\text { MPa }\end{array}$ & $\begin{array}{l}\text { Ultimate } \\
\text { Strength, } \\
\mathrm{MPa}\end{array}$ & $\begin{array}{c}\text { Total } \\
\text { Elongation, } \\
\underline{\mathscr{q}}\end{array}$ & $\begin{array}{c}\text { Uniform } \\
\text { Elongation, } \\
\underline{\mathscr{E}}\end{array}$ & $\begin{array}{c}\text { Strain } \\
\text { Hardening } \\
\text { Exponent. n }\end{array}$ & \\
\hline 2008-T4 & 124 & 248 & 28.0 & 24.5 & 0.250 & 190 \\
\hline 2036-T4 & 193 & 338 & 24.0 & 21.0 & 0.230 & 179 \\
\hline $5030-\mathrm{T} 4$ & 138 & 276 & 30.0 & --- & 0.300 & 172 \\
\hline $5182-\mathrm{O}$ & 131 & 276 & 26.0 & 23.7 & 0.312 & 131 \\
\hline TG25-T4 & 123 & 278 & 28.8 & 26.1 & 0.315 & --- \\
\hline 6009-T4 & 124 & 221 & 25.0 & 21.0 & 0.230 & 234 \\
\hline 6010-T4 & 172 & 290 & 24.0 & 21.0 & 0.220 & 255 \\
\hline 6013-T4 & 186 & 317 & 25.0 & 23.3 & 0.205 & 324 \\
\hline 6016-T4 & 139 & 248 & 29.0 & 21.5 & 0.236 & 221 \\
\hline 6111-T4 & 159 & 290 & 27.5 & 22.0 & 0.220 & 261 \\
\hline
\end{tabular}




\section{Outer Panels}

These applications typically require a "Class A" surface (no Luder lines, surface defects or orange peel) and good dent resistance. These surface requirements preclude the use of many conventional $5 \mathrm{XXX}$ alloys due to their Ludering behavior. Different auto makers specify different strength requirements to achieve dent resistance. Auto makers in the U.S.A. typically require higher strength outer panel alloys (yield strength $>207 \mathrm{MPa}$ ) to achieve dent resistance while Japanese manufacturers sometimes specify lower strength alloys (138 $\mathrm{MPa}<$ yield strength $<172 \mathrm{MPa}$, for example). Outer panels must also be formable. In addition to stretchability and drawability, certain parts require stringent flat hem capabilities for joining. To meet the dual needs of formability and strength, alloys have been developed for these applications which are formed in a relatively soft condition where formability is high (-T4 temper) and age-harden during paint bake cycles ( 30 minutes at $190^{\circ} \mathrm{C}$ for instance) to achieve needed dent resistance. Heat-treatable sheet alloys typically considered for outer hang-on applications include $2036,6009,6010,6016,6111$ and 6383 . The strengthening precipitate in 2036 is $\Theta^{\prime}$, a precursor to $\mathrm{Al}_{2} \mathrm{Cu}$, while the primary strengthening precipitate in the other alloys is $\mathrm{B}^{\prime}, \mathrm{Mg}_{2} \mathrm{Si}$. For outer hang-on parts which have lower strength requirements, conventional solid-solution strengthened 5XXX alloys may be specified if the related surface problems can be overcome. Recently developed 5XXX type alloys that contain copper, such as 5030 and TG25, require a solution heat-treatment to achieve the required properties and performance. Consequently, these alloys are actually formed in the -T4 temper. If flat hemming is a part requirement, the $2036,6010,6111$ and 6383 alloys may not be adequate.

\section{Inner Panels}

Inner hang-on panels include such components as inner hoods, deck lids, and doors. Formability is typically the limiting requirement for these types of parts, and surface requirements are less stringent. The most formable automotive sheet alloys include 2008, 5030, 5182, 6009, 6016, and TG25. Specific part complexity usually determines which alloy is most appropriate. However, scrap compatibility can also be an issue. If dent resistance and/or surface requirements eliminate $5 \mathrm{XXX}$ alloys for use as outer hang-on components, then they may also be precluded for use as inner hang-on parts because of the lower scrap value for $5 \mathrm{XXX} / 6 \mathrm{XXX}$ and $5 \mathrm{XXX} / 2 \mathrm{XXX}$ alloy mixes.

\section{EMERGING MATERIALS}

Auto manufacturers would like a low cost aluminum alloy sheet product which provides the formability, strength, weldability and finish of the best steel sheet along with the corrosion resistance of the best aluminum alloy sheet. Meanwhile, environmental concerns are tending to reduce the temperature of the paint bake, and economic concerns are tending to reduce its time. To meet these needs, some aluminum producers are attempting to develop alloys which achieve the target formability in the T4 temper and still reach the desired strength after short, low temperature thermal treatments [4]. Other producers are trying to solve the Ludering problem with $5 \mathrm{XXX}$ alloys to meet auto manufacturers needs.

\section{BUMPERS}

Bumpers, bumper reinforcements and bumper face bars require combinations of strength and toughness that can only be achieved with a heat-treatable alloy. These components are iypically made from 7XXX series aluminum alloys but they can also be made from $6 \mathrm{XXX}$ series alloys such as 6013 . The highstrength $2 \mathrm{XXX}$ alloys are not used because of their generally lower corrosion resistance.

\section{9 and 7021}

Alloys 7029 and 7021 have typically been specified for bumper components. Alloy 7029 is primarily used in the extruded form, but sheet is also used to fabricate some bumpers. The key strengthening elements in these alloys are $\mathrm{Zn}$ and $\mathrm{Mg}$. Because $\mathrm{Al}-\mathrm{Zn}-\mathrm{Mg}$ alloys harden indefinitely at room temperature following solution heat-treatment, bumpers are not formed from products in the -T4 temper. Instead, higher formability materials in the annealed (-O temper) or solution heat-treated (-W temper) condition are utilized. After forming, the bumpers are normally artificially aged to develop a very effective hardening precipitate, the $\eta^{\prime}$ phase $\left(\mathrm{MgZn}_{2}\right.$ type), prior to assembly. Adequate quench rates following solution heat-treatment are required for 7021 and 7029 to develop maximum strengths. 
In general, products made from alloy 7029 have recrystallized grain structures which provide good resistance to exfoliation corrosion. However, 7029 products can develop stress corrosion cracks under conditions involving high sustained stresses, especially when they are welded. Consequently, it is recommended that alloy 7029 not be welded. Alloy 7021 is used primarily for bumper reinforcement applications. Its strength is similar to that of HSLA steels enabling gauge for gauge substitutions which, in turn, result in 55-60\% weight savings for beam applications. A partially recrystallized grain structure (resulting from $\mathrm{Zr}$ containing dispersoids and controlled processing) combined with proper thermal treatments by end users generally results in good resistance to stress corrosion cracking and exfoliation. However, like 7029, the 7021 alloy is weld crack sensitive. Consequently, welded products have lower SCC resistance.

\section{$\underline{6013}$}

Alloy 6013 is a weldable aluminum alloy which can be used for automotive applications requiring high strength. Welded components are resistant to SCC. Candidate 6013 components include welded, stamped or roll-formed bumpers as well as any other structural automotive application requiring higher strengths. Although alloy 6013 exhibits strengths which are similar to alloys 7029 and 7021 , it is not considered weld crack sensitive. As with 7029 and 7021, alloy 6013 has strengths similar to HSLA steels which result in weight reductions of up to $60 \%$. Because microstructure/property relationships for 6013 were discussed in a previous section concerning aircraft fuselage skin, they will not be repeated here.

\section{EMERGING MATERIALS}

Alcoa has patented a high-strength ( $>420 \mathrm{MPa}$ ) $7 \mathrm{XXX}$ alloy product for use as automotive bumper sheet [5]. It has formability adequate to make typical bumper shapes in the O-temper and is capable of being slowly cooled after subsequent solution heat treatment to retain the formed shape. Strength by $\eta^{\prime}$ precipitates is developed during short aging practices which are suited to the auto industry. The sheet develops a high resistance to exfoliation corrosion of EA degree and has shown no evidence of stresscorrosion in the $3.5 \% \mathrm{NaCl}$ alternate immersion test at a stress of approximately $225 \mathrm{MPa}$. The unique combination of properties is attributed to careful control of the amounts and ratios of the major alloying elements zinc and magnesium, strict limits on the amount of copper and the use of zirconium plus proper thermomechanical treatments to produce an unrecrystallized grain structure. Weldability has not been evaluated, but no problems are anticipated based on experience with other $7 \mathrm{XXX}$ materials having low copper contents. Resistance to SCC of welded components has not been evaluated. This material is not yet available but could be commercialized if demand warrants.

\section{SPACE FRAME}

The structural frames of automobiles can now be designed with thin-wall, hollow extrusions which are joined by ductile die castings, Figure 2 .

\section{Extrusions}

Alloys used for the structural extrusions must be strong enough to carry the required loads and tough enough to absorb significant amounts of energy upon impact. Low solute 6XXX alloys and appropriate extrusion processes have been developed to consistently meet the strength, dimensional tolerance and crushability requirements of the space frame. Extrusion temperatures are high enough to be considered solution heat-treatments, and extrusions are quenched from these temperatures. The extrusions are typically bent into assembly components in the -T4 temper when the yield strengths are low $(\sim 100 \mathrm{MPa})$. Separate thermal aging treatments are used to develop the $-\mathrm{T} 6$ yield strength in the assembled parts. Product acceptance has been based on achieving -T6 yield strength levels of $\sim 230 \mathrm{MPa}$ while exhibiting good performance in quasi-static axial crush tests.

The general corrosion resistance of $6 \mathrm{XXX}$ extrusions is very good. In the -T4 condition, $6 \mathrm{XXX}$ alloys may corrode by pitting, while in the -T6 temper a combination of pitting and intergranular corrosion is possible. These alloys are not susceptible to stress-corrosion cracking in any condition, however. 


\section{Die Castings}

The extrusions in the space frame are joined by ductile cast nodes which are produced by Alcoa's vacuum die casting process. This process and appropriate equipment modifications have made it possible to reduce the gas content of the space frame nodes to $<5 \mathrm{~mL} / 100 \mathrm{~g}$ of metal. The low gas content and subsequent lower porosity are required for this structural application. The main elemental addition to the casting alloy is Si. Small amounts of Fe are added to reduce die erosion and eliminate the soldering of the casting to the dies. Care must be taken to minimize the presence of $\mathrm{Al}_{5} \mathrm{FeSi}$ platelets, however, because they significantly reduce toughness and ductility. Magnesium additions are also made to improve strength by precipitation of $\mathrm{Mg}_{2} \mathrm{Si}$ during aging. Castings are typically used in the $-\mathrm{T} 6$ condition; i.e., cast, solution heat-treated, quenched and aged. Yield strengths of these die castings range from 115 to $140 \mathrm{MPa}$, and elongation values range from 18 to $22 \%$.

These products exhibit pitting corrosion in predictive tests consisting of alternate immersion $(3.5 \% \mathrm{NaCl}$ solution, ASTM G44 for 0.5 year) and acidified saltwater spray (ASTM G85-A2 after 4 weeks). No susceptibility to stress-corrosion cracking has been observed.

\section{SUMMARY AND CONCLUSIONS}

The aluminum industry has a history of responding to the needs of airplane manufacturers for improved materials. One need, that of high strength combined with high corrosion resistance, led to the development of the T77 temper. Alloy 7150-T77 products offer significantly higher resistances to exfoliation corrosion and to SCC with no loss in mechanical properties relative to those of 7150-T6. The latest materials for compressively loaded structure, 7055-T77 plate and extrusions, develop about $10 \%$ higher specific strength compared to similar products in 7150-T6 and have significantly improved durability and damage tolerance. In addition, alloy 7055-T77 forgings are being developed. Preliminary data indicates that they offer superior combinations of strength, fracture toughness and resistance to SCC.

Al-Li alloys 2090,8090 and 2091 were developed to slow the advance of polymer matrix composites in aircraft structure contemplated by the high fuel prices of the 1970s. Technical problems slowed their development, and the reduced value of saving weight because of low jet fuel prices has, thus far, relegated them to niche applications because they are more costly than other aluminum alloy products.

The standard material for fuselages of jetliners is alclad 2024-T3 sheet, and several new materials are attempting to replace it. Alloy 2091 and 8090 sheet and Al-Mg-Si alloy 6013-T6 sheet as well as GLARE, a structural laminate of glass fibers and aluminum alloy sheet, are all being evaluated for fuselage skin materials. A new 2XXX alclad sheet and plate product for fuselage skins has been selected for use on the Boeing 777 because its exceptionally high fracture toughness permits weight savings by elimination of tear straps.

The high specific modulus and low density of $\mathrm{Al}-\mathrm{Li}$ alloy products and laminates of either aramid or glass fibers and aluminum alloy sheet make them strong candidates to regain the empennage which has been lost to graphite-epoxy composites for some jetliner applications. Discontinuously reinforced aluminum matrix composites may also be competitive for this application.

Alloy 8090 plate and 7475 plate are being considered for the lower wing of the proposed high capacity jetliner because they can both be age formed more readily than either 2024-T3 or 2324-T39.

Materials which are either under development or are being considered for development for aircraft applications include new $\mathrm{Al}-\mathrm{Li}$ alloys and discontinuously reinforced aluminum matrix composites which develop acceptable toughness by extrinsic toughening mechanisms. Amorphous aluminum alloy products are still at bench scale, but the extremely high strengths make them potentially attractive for compressively loaded applications.

As with aircraft, requirements for structural automotive components depend on the application. Hang-on components that are visible (outer panels) require Class 1 surface and good formability. The strength level required depends on the philosophy of the auto manufacturer; European and U.S. 


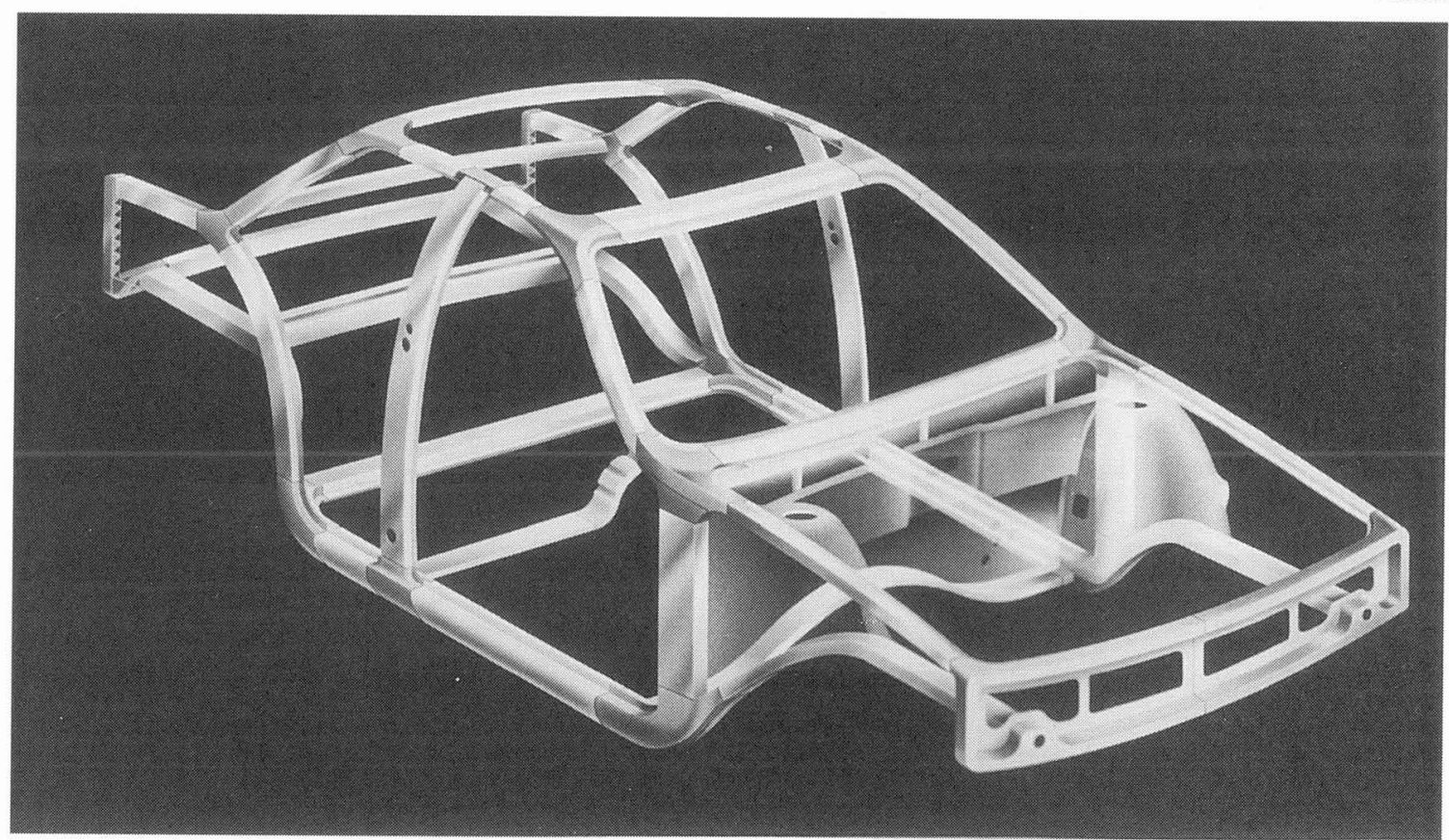

This Rendering of a Generic Spaceframe Illustrates the Use of Less than 100 Aluminum Extrusions and Interconnecting Aluminum Die Cast Nodes which are Robotically Welded to Form the Car Body. A Limited Number of Aluminum Sheet Components (i.e. Inner Fenders, Floor Pan) are then Attached to Complete the Body. 
manufacturers demand the higher strength. To respond to these needs, heat treatable sheet alloys were developed which provide adequate formability in the -T4 temper and high strength after paint baking. Hang-on components that are not visible (inner panels) require the highest formability, but their required strength levels are lower. Both heat treatable and strain hardenable alloys were developed for this application. Work continues to meet the challenges of developing a low cost aluminum alloy sheet which has the desirable characteristics of steel auto body sheet.

Heat treatable alloys are required for bumpers because of the requirements for high strength. A new alloy promises higher strength than HSLA steel with good resistances to corrosion and exfoliation corrosion.

The space frame requires thin extrusions which have tight dimensional tolerances, moderate strength and the ability to absorb energy in a predictable manner during a crash. $\mathrm{A} 6 \mathrm{XXX}$ alloy having these characteristics is being implemented. Ductile die castings which serve as nodes in the space frame have been developed using a vacuum process and a carefully controlled composition containing high Si and low Mg.

The current activity demonstrates that aluminum suppliers are continuing to develop new aluminum alloy products whether the need is for aircraft materials to counter the use of polymer matrix composites or for automotive materials to replace steel.

\section{ACKNOWLEDGMENTS}

The authors would like to thank R. L. Rolf for his contributions on the property requirements for aircraft applications and S. J. Murtha and H. T. Weykamp for fruitful discussions concerning the automotive applications.

\section{REFERENCES}

[1] J. T. Staley and R. L. Rolf, "Trends in Alloys for Aircraft," to be published in Proceedings of International Symposium on Light Metals, The Metallurgical Society of CIM, 1993.

[2] E. Balmuth, "Aluminum-Li Alloy for Thick Section Applications," presented at TMS-AIME Meeting at Denver, CO, February 1993.

[3] J. M. Story, G. W. Jarvis, H. R. Zonker and S. J. Murtha, "Issues and Trends in Automotive Aluminum Sheet Forming," SAE SP-944, Proceedings of Sheet Metal and Stamping Symposium, Detroit, MI, March 02-04, 1993, pp. 1-25.

[4] M. J. Bull, P. E. Fortin and D. M. Moore, "An Optimized Aluminum Alloy (X6111) for Auto Structural Applications," Light Metal Age, December 1984, p. 28.

[5] B. W. Lifka, U.S. Patent 4,629,517. 